\title{
Problem-Based Learning for an Electrical Machines Course
}

\author{
https://doi.org/10.3991/ijet.v15i22.16871 \\ Juan-Carlos Cobos-Torres ${ }^{(凶)}$, Pablo Arias Reyes, Carlos Fernando Mendez \\ Catholic University of Cuenca, Cuenca, Ecuador \\ juan.cobos@ucacue.edu.ec
}

\begin{abstract}
This article seeks to describe the implementation of a problembased learning (PBL) teaching-learning method in a university classroom. The aim is for the student through given real-life situations to acquire knowledge, abilities, and attitudes in the subject of electrical machines in the undergraduate electrical engineering program of the Catholic University of Cuenca. Solving problems related to static machines will be similar to the problems that students will face in their professional lives; namely, to be able to identify a static machine and its operation, parameters, model its equivalent circuits (open- and short-circuit tests), calculate losses, and carry out hysteresis loop measurement. Most of these concepts are abstract and challenging for students to assimilate. Therefore, the present research shows how using the PBL model in studying static machines improves the academic performance and achievement of students in an experimental group. There was an improvement of 7 points out of 100 in relation to the average of the grades of three groups of students from previous semesters. Also, the standard deviation is lower in the experimental group (SD 4.5584), which shows that most of the students improved in their performance. Finally, there was no failure of the study year nor remedial exams among this group.
\end{abstract}

Keywords - Continuing education, Simulation, Electrical engineering, Problem based learning, Static Machines

\section{Introduction}

Static machines are one of the fundamental subjects in an electrical engineering program. Nowadays, despite having many technological tools, theory/lecture classes are still used, which makes learning a mandatory and monotonous experience for the student. Evolution of the teaching-learning process is imperative for all universities in the new millennium; however, this does not mean that the existing teacher-centered approach and theory classes are poor. The educators of the Catholic University with the support of their superiors always seek to rethink learning models with the aim of enabling students to meet the demands of professional practice. With this approach in mind, the academic staff has been trained in the PBL approach and are motivated to apply it in their subjects. As set out in [1], PBL should be used with the goal of acquiring new knowledge, which is based on the resolution of problems. 
In the '60s, McMaster University saw the need to overhaul their education. Their medical students, despite having excellent theoretical contents, were not able to put them into practice. It was clear that the graduate profile required problem-solving abilities. The student had to be able to acquire information through hypothetical-deductive reasoning, synthesize the information in search of possible hypotheses, and then prove such hypotheses by acquiring additional information [2].

PBL engages students in active, motivated, and cooperative learning, which is associated with independent learning [1]. Its main features are meaningful learning through student commitment and better learning planning through holistic problems. Furthermore, it awakens critical thinking in the students as professors stimulate thought and guide the search for information. The aims of the subject can be approached through real-life problems and situations. Finally, PBL promotes multidisciplinary as the students must draw upon knowledge from various disciplines.

Thus, [4] analyzes the advantages and disadvantages of using PBL in the teaching of specialized subjects in electrical engineering, as the reticence exists that it does not properly cover the technical contents required. The authors assert that the proper use of PBL makes it possible to offer the same or more technical content than traditional teaching methods in a specialized course. Similarly, [5] details how an electrical problem can be solved by means of PBL; better learning outcomes are obtained compared to the classical method. Other applications of PBL in teaching within electrical engineering can be expounded upon; for example, in the electrical drives course [6], electric vehicles [7], differential equations [8], among others, and all of them have promising results.

Within the subject of Electrical Machines, the study of the electrical transformer as a static machine has a crucial role. Electrical energy transmission and distribution networks function correctly as a result of the operating principle of the electrical transformer, which allows for modification of the voltage and current values to appropriate levels for transmission or distribution, always maintaining the frequency and power stable. This reduces costs and losses that would be produced in energy transmission at low voltage levels. The electrical transformer is useful due to the economic savings it produces when carrying out high-voltage power transmission. There are a variety of losses that occur in transformers. Foucault or parasitic currents are one of the biggest problems that can come up in a transformer, reducing the electrical efficiency of the transformer.

Energy in the transformers is lost essentially in heat form inside the core. It is beneficial to analyze the magnetic circuit and the electrical circuit separately, as each undergoes losses in entirely different manners. In [9], the authors explain that the losses are directly related to the heat produced and are composed of the no-load losses and load losses. Similarly, [10] indicates that the core is responsible for transmitting the magnetic flux produced by the windings of the transformer, which must be manufactured with soft magnetic materials with a low reluctance to reduce the losses that occur in its inside. But the most important thing is the assertion that in the manufacturing of the core not only should greater efficiency in the magnetization be sought, but rather a reduction of the losses that can be produced by parasitic currents inside it should also be sought. All this is complemented by the idea put forward by [11] that alternating 
flux, apart from inducing an electromotive force in the transformer windings, also induces small currents in the core that act on the surface and produce heat. The magnetic induction will also depend on the material of the metal plate (sheet) [12] based on the percentage of carbon obtained from the chemical composition of the steel sheet to the silicone [13].

The transformer has to bear all losses and the nominal power rating for which it was designed. Students must become aware of and understand energy efficiency and the environmental impact produced by losses inside the core, and how these affect the environment [14], [15]. There are various properties and physical characteristics of the transformer parts that determine the losses; for example, electrical resistance, thermal conductivity, magnetic saturation, coercive force, residual induction, and permeability [16]. Many of the concepts mentioned above are abstract and challenging for students to understand. For this reason, the use of PBL has been proposed in order to encourage students to adopt the attitude required in their future professional career and to incite motivation for learning.

\section{Materials and Methods}

Static electrical machines are a professionalizing subject in the fourth semester of the Electrical Engineering program of the Catholic University of Cuenca. It is a fiveECTS credit course (System approved by the committee of Higher Education in Ecuador). It has an expected workload of 200 hours of theory and 40 hours of practical activities. The course has two expected results. Firstly, students will be able to interpret the modeling of real and ideal transformers, applying the theory of static electrical machines and phasor diagrams as well as its single- and three-phase equivalent circuits. Also, students will simulate losses to apply them in practical electrical networks. Secondly, students will be able to identify the modeling of transformers to apply them in conventional electrical networks.

In addition to the preliminary learning objectives mentioned above, students will improve other abilities that are important for their future career, including teamwork, team management, time management, oral presentation, and technical writing skills.

\subsection{Implementation of the P-based learning method}

Problem-based learning is based on the premise that students have the responsibility to learn, so there were no homework or attendance obligations and submitting papers was not mandatory. Each class session (four hours per week) was organized so that the professor would share a problem with the students. A brief introduction of the chosen topic is given as well as encouragement towards self-learning. Various kinds of information are provided, but above all virtual and interactive information. The operating principle of static machines is complex to understand by the explanations, formulas, and graphs that are usually found in textbooks. Therefore, videos, animations, and simulations are used to visualize the operation of the transformers. In line with this vision, students become acquainted with a vast bibliography, which is always widening as a 
result of their own research. The aim is to break away from traditional classroom practices; for example, having one specific textbook.

The learning outcomes of the course are presented in Table 1. It was proposed that each learning objective would be achieved by presenting and solving a problem. The aim is to prioritize a student-centered learning approach. Small groups of students, who learn collaboratively, are formed to solve a problem so that self-directed learning skills are developed [17]. The basic concepts of electrical machines are multidisciplinary and require knowledge of physics, magnetism, electrical circuits, and advanced math. Hence, students must have proficiency in magnetism and solving electrical circuits and basic skills in using MATLAB Simulink.

Table 1. Linking topics - Problems raised

\begin{tabular}{|c|c|c|}
\hline Week & Readings & Problems \\
\hline $1-3$ & $\begin{array}{l}\text { Introduction to the course objectives and } \\
\text { work principles } \\
\text { Electromagnetic principles } \\
\text { Magnetic Circuits } \\
\text { Hysteresis }\end{array}$ & $\begin{array}{l}\text { Summary: How to use MATLAB Simulink? } \\
\text { Could it be possible to generate a video that explains } \\
\text { concisely the main electromagnetic principles? } \\
\text { To what extent can one simulate and analyze the mag- } \\
\text { netic circuits of a static machine with MATLAB? } \\
\text { Is it possible to characterize the hysteresis curve with a } \\
\text { two-channel oscilloscope? }\end{array}$ \\
\hline $4-8$ & $\begin{array}{l}\text { Equivalent circuit of the real transformer } \\
\text { Short-circuit and open-circuit tests on } \\
\text { transformers } \\
\text { Voltage and efficiency regulation } \\
\text { Transformer tap-changers } \\
\text { Single-phase autotransformer }\end{array}$ & $\begin{array}{l}\text { There are several transformer simulators. Would it be } \\
\text { possible to find the equivalent circuit of the transformers } \\
\text { in the laboratory? } \\
\text { Now that you know some concepts, could you apply } \\
\text { them to develop the open- and short-circuit test in the la- } \\
\text { boratory? What happens with these tests if you change } \\
\text { the core between solid and laminated? } \\
\text { With the results obtained, can you calculate losses, regu- } \\
\text { lation, and efficiency? } \\
\text { What are the differences, advantages, and disadvantages } \\
\text { between a transformer and an autotransformer? }\end{array}$ \\
\hline $8-12$ & $\begin{array}{l}\text { Bank of transformers in a three-phase } \\
\text { connection } \\
\text { Equivalent Circuits } \\
\text { Harmonics }\end{array}$ & $\begin{array}{l}\text { Could you assemble a bank of transformers and try the } \\
\text { different possible connections? } \\
\text { With the transformer simulators, would it be possible to } \\
\text { find the equivalent circuit of the banks? } \\
\text { With the energy quality team, would you be able to visu- } \\
\text { alize the harmonics in the bank of transformers? }\end{array}$ \\
\hline $12-15$ & $\begin{array}{l}\text { Three-phase connections using two trans- } \\
\text { formers } \\
\text { Special Transformers }\end{array}$ & $\begin{array}{l}\text { Is it possible to generate a three-phase connection with } \\
\text { only two transformers? } \\
\text { There is a wide variety of special transformers. Are you } \\
\text { able to synthesize their types and applications through } \\
\text { an interactive presentation? }\end{array}$ \\
\hline
\end{tabular}

Problems are organized progressively, starting with the static machine, moving on to the area of single-phase and three-phase real transformers, and finishing with the area of special transformers. The results of the resolved problem are the basis to solve the next problem. For example, one of the first problems was to design a transformer core and interchangeable coils. These were the basis for solving the next problems. These transformers can be seen in Figure 1. These figures completely you do. 


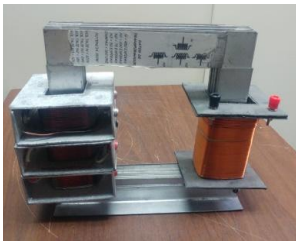

(a) Laminated Core

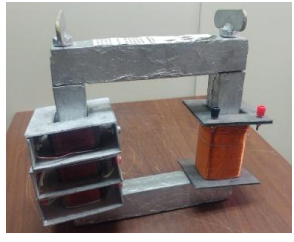

(b) Solid

Fig. 1. Transformer with

At the start, as it was a new methodology, the students due to slackness did not solve problems successfully or did not organize themselves satisfactorily. As time went by, however, they realized that each problem is linked to the next, and they asked for more academic tutoring. The tutoring program was organized to guide students to solve the problems raised. Although the first classes were attended by $30 \%$ of students, later on in the semester additional classes were requested for the problems, with $100 \%$ attendance; therefore, tutoring hours became intergroup work. Students discussed the problems with the professor and among themselves, the professor guiding them when necessary. Additionally, during tutoring, students had to submit their progress and results in solving the problems. Students had to write a professional report on each topic that included an introduction with the related theory, a description of the model developed, the results of the simulation or practice, analysis of the findings, conclusions, and recommendations. Students learned how to simulate in Matlab and design figures and data to clearly show the phenomena analyzed.

Another example of the link between problems is the short- and open-circuit tests on laminated and solid-core transformers can be seen in Figures 2 (a) and (b).
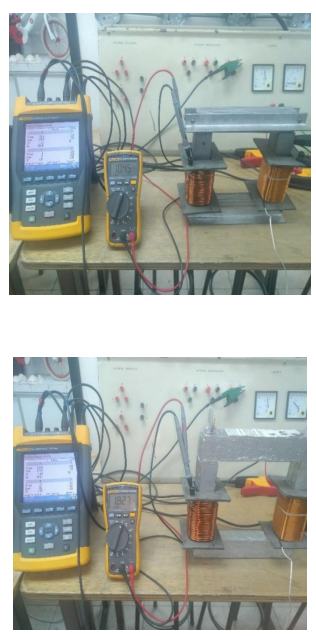

(a) Laminated Core
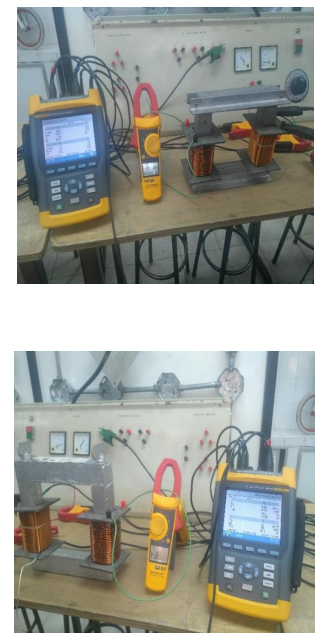

(b) Solid Core

Fig. 2. Open-Circuit and Short-Circuit Test on Transformer with: 
MATLAB 2019 has an example to model a personalized electric transformer which shows hysteresis using the block (see Figure 3).

However, the course requirement is that students develop their own personal simulation models for each problem, which means that they must develop the proposed simulation using the reluctance with hysteresis block in a magnetic circuit. Students will learn the difference between a real and an ideal transformer. It is important to note that for each group, the problems were modified slightly to avoid the possibility of plagiarism.
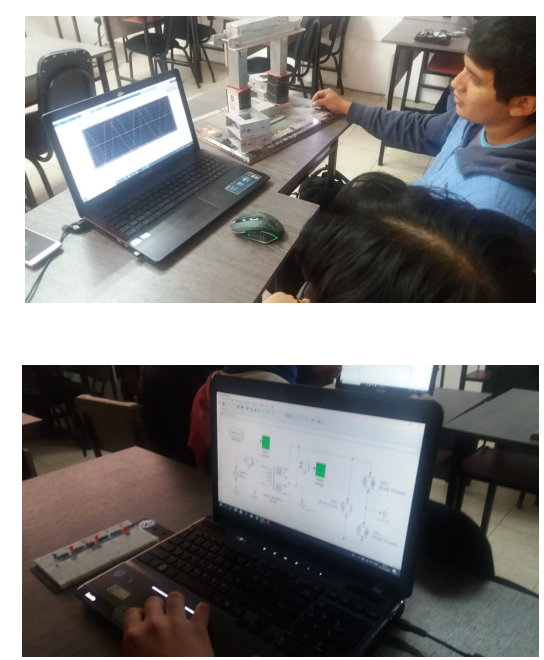

Fig. 3. Students simulating using MATLAB.

At the end of the course, an expository class about static machines is organized. Students choose a topic to present. The topic is of their choice and should be backed up by a technical report. A conference article template was chosen. The results are presented in approximately 15 minutes. The arguments are, for example, quantification of transformers losses in the distribution systems, simulation of losses in three-phase transformers, analysis of harmonics in transformers windings, analysis of hotspots in transformer stations.

\subsection{Evaluation}

As already stated, problem-based learning does not impose obligations on students; the student must become aware of and responsible for his own learning. Students work individually to solve the problems in the first two topics. It is a way to guide the learning process individually. Subsequently, in the other two topics, students work in groups of three or four. It is interesting to observe how some students focus their attention more on the theoretical part than the practical part. This practice is an enriching experience, as the professor tries to assign the students into heterogeneous workgroups. That way they can unite their different strengths in group work. Some of the groups can 
independently solve the problems raised and then support other groups that need more help.

Each problem report is commented upon and evaluated by the other groups and the professor. The minimum passing grade for the course is 70/100. To improve their grades, students can do extra work or help other groups that need more help. In the final evaluation, which is obligatory and cumulative, the aim is for students to think critically, which is why reasoning, explanatory, and analytical questions are included.

\section{$3 \quad$ Results}

The number of students who attended previous courses was 9 for the semester from September 2016 to February 2017, 16 for the semester from September 2017 to February 2018 (during the semester from March to August 2017, there were no such classes due to a lack of students), 28 for the semester from March 2018 to August 2018, and 22 for the semester from September 2018 to February 2019. The grades from the previous semesters from 2016 and 2018 are presented in Figure 4 (a). The average grade increased and the standard deviation decreased in the new PBL-based course. Conversely, in previous semesters, when courses were based on lectures, the differences between grades were more notable. The talented students were able to, one way or another, reach the learning objectives through the traditional learning method, but many students did not reach the objectives. During the PBL-based semester, fewer than $20 \%$ of the students failed to solve all the exercises. The exam was not mandatory if they had presented all the reports with the solution of the problem raised as well as the exercises presented in the tutoring. Only $35 \%$ of students took the exam, and $90 \%$ obtained good grades. As Figure 4 (a) shows, the experimental group (Sep18_Feb19) got an average grade of $89 / 100$ in comparison to the previous semesters, which obtained average grades of $74 / 10,71 / 100$, and $74 / 100$ respectively.

Figure 4 (b) shows that grade dispersion is much lower for the experimental group. As Table 2 shows, the experimental group has a standard deviation of 4.5584. On the other hand, the other groups have a standard deviation of 4.8477, 11.7580, and 11.5676, respectively

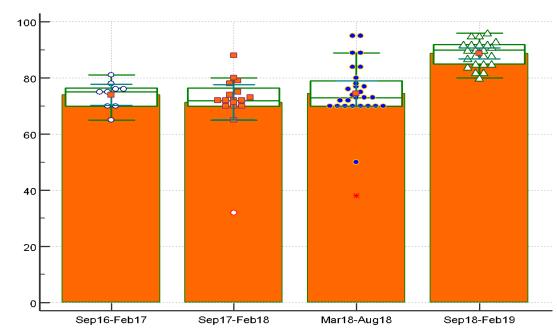

(a) Course Grades

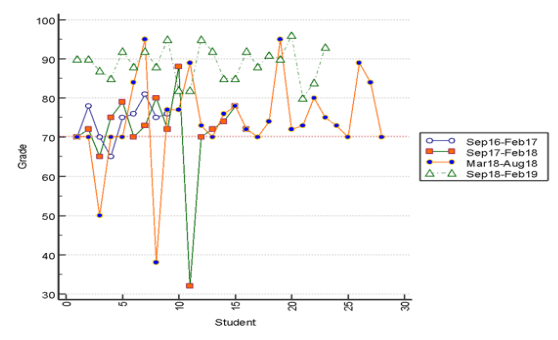

(b) Semester control chart.

Fig. 4. 
It is important to analyze that in the non-experimental groups, there were grades less than 70/100; this can be seen in Figure 4 (b). In the case of the Sep17_Feb18 and Mar18_Feb19 semesters, there were cases of school drop-outs due to the complex content of the subject, which also can be seen in Table 2 in the lowest grades, 32/100 and $38 / 100$, respectively.

Table 2. Overall grade of each semester. Statistical analysis

\begin{tabular}{|l|c|c|c|c|}
\hline & Sep16_Feb17 & Sep17_Feb18 & Mar18-Aug18 & Sep18-Feb19 \\
\hline Sample size & 9 & 16 & 28 & 23 \\
\hline Mean & 74.00 & 71.3750 & 74.4286 & 88.7273 \\
\hline Standard deviation & 4.8477 & 11.7580 & 11.5676 & 4.4615 \\
\hline Lowest grade & 65 & 32 & 38 & 80 \\
\hline Highest grade & 81 & 88 & 95 & 96 \\
\hline
\end{tabular}

\section{Discussion}

Research and engagement with society and academia are university responsibilities; its results are fundamental pillars for the scientific and technological development of a country. Several developed countries have centralized their source of manufacturing and production in countries with lower wealth; for countries such as Ecuador, production and technological development are imported.

Ongoing scientific and technological advances, internationalization (student mobility), the need to develop specific skills and attitudes, gender issues, and the need to expand governmental involvement demand attention to improve the quality and relevance of engineering programs and to update them to meet the realities of the 21 st century, allowing for the design and implementation of dynamic programs of educational innovation.

The incorporation of methodologies that abet meaningful learning and the use of Information and Communication Technologies (ICT) is a requirement for all college students, given that they are determining factors in putting together their graduate profile. In addition to this, there is the societal pressure for the universities to commit in a more determined manner, so that the knowledge that is generated in the universities by research and teaching is transferred to the wider public in order to transform it and provide added value [18].

Based on this background, this article describes the implementation of the ProblemsBased Learning teaching approach in the Academic Unit of Engineering, Industry, and Construction, specifically in the Faculty of Electrical Engineering. The analysis focuses on the interaction between members (professors-students) on a common topic, where each contributes and at the same time derives permanent benefit from the group. The analysis can be summed up by the performance and attitudes observed in the students during the course of the experience, which were recorded in reports by professors and the statements of students obtained at the end of the academic periods [19].

Students indicated high levels of satisfaction, reflecting high acceptance and liking for the methodology used, even though at the beginning there were some difficulties 
until it was fully understood. On the other hand, from the perspective of the professor, it is rewarding to work on training projects. The enthusiasm of the students, who were accustomed to staying in the classroom, listening to the teacher, for activities that challenged them was notable. During the classes and presentations, the students linked the educational contents examined with the causes and possible solutions to the problem; that is to say, the theoretical content was contextualized, which led to a better understanding of it [4].

It is clear that students feel more committed to the project when they are more involved in the decision-making process at every stage. That is why teachers should seek consensus and move away from authoritarian attitudes. Taking into account the limited time that was available for the course, the problem was proposed at the start by the professor and the student, based on the future use of the subject in their professional practice. Consequently, the starting point was to generate ideas about how to approach the problem from different angles. A possible improvement of the experience is that students could raise issues from their own interests based on observations about their future working environment instead of working on a problem raised by the professor.

The main difficulties detected in the process were differences standing in the way of reaching an agreement about how to work as a group, types of subjects that did not directly contribute towards solving the problem at hand, and the coordination of timetables. These disadvantages were all significant factors affecting the assessment of the final project.

Research competitions subsume collaborative work, data collection techniques and dissemination of research results, both orally and in writing, the skills and abilities that the students develop to gather information from documentary sources as well as the field and to present the research results in front of the group; finally, the interest in the course.

\section{Conclusion}

The introduction of innovative methodologies that dare to break traditional learning processes challenges all participants in the field of education. The main responsibility of the modern professor is to awaken in the student the capacity to identify a problem. The professor should go further, however, and instill in the student the practice of analyzing all possible solutions to said problems. On the other hand, the student should seek to understand abstract concepts. It is important that the student carries out and backs up assessments while searching for innovative solutions. Only then will the professor and student be able to actively build knowledge in the classroom. The comparative results in this study are an important point of reference in this regard. It can be concluded that the students truly internalized the skills learned. This helps the student to show more insight when facing a problem, his scientific curiosity piqued, armed with an open mind upon observing the problem to be solved, from which an interdisciplinary affinity is created that will be a fundamental pillar of their professional life. 


\section{Acknowledgement}

The research leading to these results has received funding from Smart University 2.0 program, funded by "Optimización energética del sistema de recaudo en Unidades de Transporte Urbano".

\section{$7 \quad$ References}

[1] Barrows, H. S. (1986). A taxonomy of problem-based learning methods. Med. Educ, 20 (6), 481-486.

[2] Palacios, M.; González, J. G.; Ocampo, J. L. (2017). Aprendizaje basado en problemas para la enseñanza de los PLC en la Universidad Tecnológica de Altamira. RIDE. Revista Iberoamericana para la Investigación y el Desarrollo Educativo, 8 (15), 566-581. https://doi.org/10.23913/ride.v8i15.311

[3] Excey, K.; Dennick, R. (2007). Enseñanza En Pequeños Grupos en Educación Superior: Tutorías, Seminarios y Otros Agrupamientos, 1st ed.; Narcea Ediciones: Madrid, España, pp. 85-102.

[4] Hosseinzadeh, N.; Hesamzadeh, M. R. (2012). Application of project-based learning (PBL) to the teaching of electrical power systems engineering. IEEE Transactions on Education. 55 (4), 495-501. https://doi.org/10.1109/te.2012.2191588

[5] Bütün, E. (2005). Teaching genetic algorithms in electrical engineering education: A problem-based learning approach. Int J Electr Eng Educ. 42 (3), 223-233. https://doi.org/10. $\underline{7227 / \text { ijeee.42.3.2 }}$

[6] Sedaghat, A.; AlJundub, M.; Eilaghi, A.; Bani-Hani, E.; Sabri, F.; Mbarki, R.; Assad, M. E. H. (2017). Application of PBL in the course fluid and electrical drive systems, case study: Manufacturing an automated punch machine. Journal of Problem Based Learning in Higher Education. 5, (2), 48-58.

[7] Gonzalez-Rubio, R.; Khoumsi, A.; Dubois, M.; \& Trovao, J. P. (2016). Problem-and projectbased learning in engineering: A focus on electrical vehicles, Proceedings of the IEEE Vehicle Power and Propulsion Conference (VPPC), Hangzhou, China. https://doi.org/10. $1109 /$ vppc. 2016.7791756

[8] Santos, LB, Xavier, PHF, Santos, JVC y Sampaio, RR (2020). Enseñanza de ecuaciones diferenciales ordinarias utilizando los supuestos del método PBL. Revista Internacional de Pedagogía de Ingeniería (iJEP), 10 (3), 7-20.

[9] Hernández R. D. (2015). Modelamiento de los Transformadores de Distribución para Estudios de Armónicos, Comportamiento de las Protecciones de Sobrecorriente, Pérdidas de Energía y Disminución del Tiempo de Vida, aplicado en la Empresa Eléctrica Ambato SA, Grade Level, Escuela Superior Politécnica del Litoral, Guayaquil. https://doi.org/10. 21931/rb/2018.03.01.7

[10] Alcón Mesa, J. L. (2010). Estudio de la Capacidad de Carga segura en Transformadores de Potencia, Grade level, Universidad Carlos III de Madrid., Madrid. https://doi.org/10. 24137/raeic.7.13.13 
[11] Maigua, A.; Alberto, L. (2010). Modelo Térmico de Diagnóstico de un Transformador de Potencia, Grade level, Universidad Técnica de Cotopaxi, Cotopaxi. https://oi.org/10. 29018/978-9942-792-61-7

[12] Staff, E. (1965). Circuitos Magnéticos y Transformadores: Estudio Amplio de las Características Físicas de los Circuitos Magnéticos y de su Aplicación al Cálculo y Diseño de los mismos y de los Transformadores, 1st ed.; Editorial Reverté SA: Massachusetts, EEUU. https://doi.org/10.6035/infitec.2004.18

[13] Oda, Y.; Toda, H.; Shiga, N.; Kasai, S.; Hiratani, T. (2014). Effect of Si content on iron loss of electrical steel sheet under compressive stress. IEEE Trans. Magn, 50 (4), 1-4. https://doi.org/10.1109/tmag.2013.2290321

[14] Georgilakis, P. S. (2011). Environmental cost of distribution transformer losses. Appl. Energy, 88 (9), 3146-3155. https://doi.org/10.1016/j.apenergy.2010.12.021

[15] Trianni, A.; Cagno, E.; De Donatis, A. (2014). A framework to characterize energy efficiency measures. Appl. Energy, 118, 207-220. https://doi.org/10.1016/j.apenergy.2013.12.042

[16] Lajtin, Y. M. (1983). Metalografía y Tratamiento Térmico de los Metales, 3ra ed.; MIR: Buenos Aires, Argentina.

[17] Morales, P.; Landa, B. (2004). Aprendizaje basado en problemas. Theoria, 13, 145-157.

[18] Nakayama, M., Fueki, M., Seki, S., Uehara, T., \& Matsumoto, K. (2012). A Human Resource Development Program for Information Technology Engineers using Project-Based Learning. International Journal of Advanced Corporate Learning (iJAC), 5(4), 9-15. https://doi.org/10.3991/ijac.v5i4.2234

[19] Nakayama, M., Fueki, M., Seki, S., Uehara, T., \& Matsumoto, K. (2012). A Human Resource Development Program for Information Technology Engineers using Project-Based Learning. International Journal of Advanced Corporate Learning (iJAC), 5(4), 9-15. https://doi.org/10.3991/ijac.v5i4.2234

\section{Authors}

Juan-Carlos Cobos Torres is research at the Catholic University of Cuenca, Postgraduate Sub direction. He received his Ph.D. at Carlos III University of Madrid and received his MSc degree from the same University. His main research of interest focuses on real-time computer vision techniques applicable to robotics or other demanding real-world, and real-time applications. Further, Biomedical Signal Processing with methods and algorithms based on computer analysis of biological and medical images, in particular, vital sign detection. Finally, his research interests also include e-learning in higher education, gamification learning, problem-based learning, among others. Email: juan.cobos@ucacue.edu.ec

Pablo Arias-Reyes was born in Cuenca, Ecuador, in 1974. He received the B.S. and M.S. degrees in electrical engineering from the University of Cuenca, Cuenca, in 2002 and 2013, respectively. He is Member of IEEE since 2001 and Senior Member since 2017. He has a Power systems Stability certified at San Juan University-Argentina on 2005 and an Economy of Regulation of Electricity Markets certified at San Andrés 
University-Argentina 2013. Currently, since June 2015; Pablo works as a Teacher-Researcher of the Electrical Engineering Department at the Catholic University of Cuenca in the Energy Power Area and Smart Energy Simulation Laboratory. His areas of interest are planning of systems of generation and transmission of energy, unconventional energies, electrical interconnections and stability, smart grids and systems of distributed generation.

Carlos Mendez Martinez is a professor in the Academic Unit of Engineering, Industry, and Construction at the Catholic University of Cuenca, Cuenca, Ecuador. His research interests include research methodologies, evaluation and assessment, problembased learning, and collaborative learning.

Article submitted 2020-07-06. Resubmitted 2020-08-13. Final acceptance 2020-08-13. Final version published as submitted by the authors. 